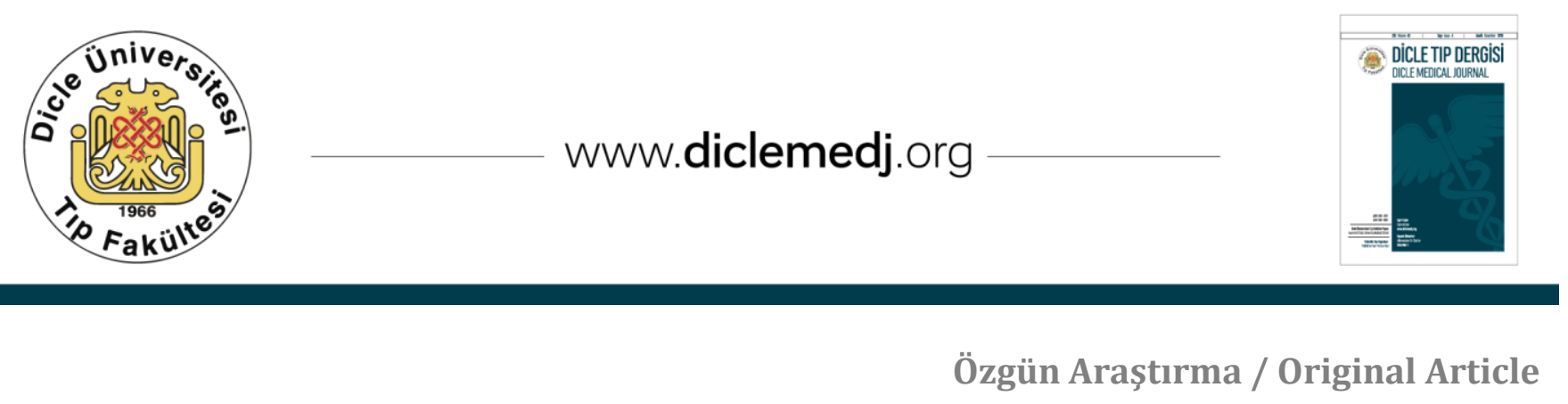

\title{
Güneydoğu Anadolu Bölgesi'ndeki Tekrarlayan Abortus Olgularında Protrombin, MTHFR, FV Leiden ve PAI-1 Polimorfizmlerinin Retrospektif Olarak İncelenmesi
}

\author{
Evren Gumus ${ }^{1}$ \\ 1 Harran Üniversitesi Tıp Fakültesi Tıbbi Genetik Anabilim Dalı, Şanlıurfa, Türkiye ORCID: 0000-0001-9932-0730
}

Geliş: 15.01.2018, Revizyon: 19.04.2018, Kabul Tarihi: 07.05.2018

$\ddot{0} \mathbf{z}$

Amaç: Tekrarlayan gebelik kaybı (TGK), 20. gebelik haftasından önce meydana gelen iki ve ya daha fazla gebelik kaybı olarak tanımlanır. TGK'na yol açan faktörlerin yaklaşık yarısı idiopatiktir, bilinen nedenler içinde ise immünolojik, endokrinolojik ve anatomik nedenler en önemlileridir. TGK'na yol açan faktörler içinde genetik nedenler \%2-5 oranında yer tutmakta ve ilerleyen gebelik haftalarındaki genetik nedenli gebelik kayıplarının kalıtsal trombofili nedenleri ile olduğu bilinmektedir.

Yöntemler: Bu çalışmada tekrarlayan gebelik kayıpları nedeni ile araştırılan, herhangi bir kromozom anomalisi olmayan 1395 hastanın MTHFR, FV-Leiden, PAI-1 ve Protrombin polimorfizmleri retrospektif olarak incelenmiştir.

Bulgular: Kalıtsal trombofili polimorfizmleri heterozigot, homozigot ve yabanıl olarak yüzdelik dilimlerle incelenmiștir.

Sonuç: Çıkan sonuçlar güncel bilgiler ışığında ve bölgesel veriler eşliğinde tartışılmıştır.

Anahtar Kelimeler: Protrombin, MTHFR, PAI-1, trombofili, tekrarlayan gebelik kaybı.

DOI: $10.5798 /$ dicletip. 457243

Yazışma Adresi / Correspondence: Evren Gümüş, Harran Üniversitesi Tıp Fakültesi Tıbbi Genetik Anabilim Dalı, Şanlıurfa, Türkiye e-mail: evreng@harran.edu.tr 


\title{
Retrospective Investigation of Prothrombin, MTHFR, FV Leiden and PAI-1 Polymorphisms in Recurrent Abortion in the Southeastern Anatolia Region
}

\begin{abstract}
Objective: Recurrent pregnancy loss (RPL) is defined as the loss of two or more gestations before the 20th gestational week. Approximately half of the factors that cause RPL are idiopathic, and immunologic, endocrinological and anatomical causes are the most important among known causes. Genetic causes account for $2-5 \%$ of the factors that cause RPL and it is known that hereditary thrombophilia are found in the genetic background of the losses in the advanced gestational weeks.

Methods: In this study, MTHFR, FV-Leiden, PAI-1 and Prothrombin polymorphisms of 1395 patients without any chromosomal anomalies were investigated retrospectively for the cause of recurrent pregnancy loss.

Findings: Hereditary thrombophilia polymorphisms were investigated with heterozygous, homozygous and wild type percentage slices.
\end{abstract}

Conclusion:The results are discussed in the light of current knowledge and in the context of regional data.

Keywords: Prothrombin, MTHFR, PAI-1, trombophilia, recurrent pregnancy loss.

\section{GíRiş}

Tekrarlayan gebelik kaybı (TGK) tanımı farklı araştırmacı grupları tarafından farklı şekillerde tanımlanmasına rağmen, en kabul gören hali ile 20. gebelik haftasından önce meydana gelen iki ve ya daha fazla gebelik kaybı olarak tanımlanır ${ }^{1}$. Tekrarlayan gebelik kaybı sıklığı, gebelik kaybı sınır sayısının 3 olarak alındığı durumda \%1-2, 2 olarak alındığ durumda ise $\% 5^{\prime}$ dir $^{2}$. Klinik olarak tanımlanabilen gebeliklerin yaklaşık \%12-15'i düşükle sonuçlanır ${ }^{3}$. TGK durumunda, yaşanan gebelik kayıpları genellikle aynı gebelik haftasında olur, bu durumun nedeni gebelik kaybında aynı mekanizmanın etkili olmasıdır ${ }^{4}$. Her gebelik kaybı sonrası bir sonraki gebeliğin düşükle sonlanma ihtimali artmaktadır. Dört düşüğü olan bir anne adayının tekrar düşük yapma riski \%40 iken, bu oran beș düşüğü olan bir anne adayında \%69'dur5. TGK'na yol açan faktörlerin yaklaşık yarısı idiopatiktir, bilinen nedenler içinde ise immünolojik, endokrinolojik ve anatomik nedenler en önemli mekanizmalardır6. TGK'na yol açan faktörler içinde genetik nedenler \%2-5 oranında yer tutmaktadır ve bu oranın büyük kısmı ilk trimestr gebelik kayıları sonucu oluşmaktadır7. İlk trimestrda gözlenen genetik nedenli kayıpların büyük çoğunluğunun nedeni kromozomal anomaliler iken, ilerleyen gebelik haftalarında gözlenen genetik nedenli kayıpların çoğunluğunu herediter trombofili oluşturmaktadır8,9. Herediter trombofililer, hiperkoagülan duruma yol açan, bireydeki tromboz riskini artıran çeşitli gen polimorfizmleridir. Bu durumun gebelikte daha da önemli olmasının nedeni, gebeliğin doğasında bulunan koagülasyon ve fibrinoliz sistemindeki değişiklikler nedeniyle artmış tromboz eğiliminin olmasıdır. Ayrıca herediter trombofililerin TGK ile olan ilişkisi uteroplasental dolaşımın etkilenmesine bağlıdır. $\mathrm{Bu}$ genler içinde üzerinde en fazla çalışma yapılanlar; Metilen Tetra Hidro Folat Redüktaz (MTHFR), Faktör $\mathrm{V}$ Leiden (FVLeiden), Protrombin ve Plazminojen Aktivatör İnhibitör-1 (PAI-1) dir10,11. Bu faktörlerden iki veya daha fazlasının etkilenmesi durumunda, gebelik kaybı riskinin artış gösterdiğini belirten çalışmalar mevcuttur ${ }^{1,2}$.

MTHFR C677T ve MTHFR A1298C polimorfizmlerin varlığ metilentetrahidrofolat redüktaz enziminin aktivitesinin azalmasıyla ilişkilendirilmiş olup tromboz açısından zayıf 
risk faktörü olarak değerlendirilmektedir ${ }^{12}$. Faktör $\mathrm{V}$ pıhtılaşma yolağında fibrin oluşumunda rol alır. Aktive Protein C, Faktör V'in inhibisyonu ve fibrin oluşumunun kontrolünden sorumludur. Leiden polimorfizminin varlığ $\quad F \quad$ V'in etkin inaktivasyonunu önleyerek pihtı oluşumuna eğilim yaratır. Homozigot mutasyonu yaklaşık 35 kat risk artışı ile ilişkilendirilmiştiri ${ }^{13}$. Protrombin koagülason kaskadında faktör Va ve Xa yardımı ile trombine çevrilmektedir. G20210A polimorfizmi durumunda tromboz riskinde 6-25 kat risk artışı meydana geldiğini gösteren çalışmalar mevcuttur. Gebelikteki tromboembolilerin yaklaşık \%17'sinden sorumludur ${ }^{14}$. PAI-1 (Serpine-1) doku plazminojen aktivatörü (tPA)'nün etkili bir inhibitörü olup, fibrinolizin düzenlenmesinde önemli rol oynar. Artmış PAI-1 aktivitesi plazminojenin plazmine dönüşümünü bloke ederek fibrinolizi inhibe eder. $5 \mathrm{G} / 5 \mathrm{G}$ yabanıl genotip olup, $4 \mathrm{G} / 5 \mathrm{G}$ ve $4 \mathrm{G} / 4 \mathrm{G}$ artmış $\mathrm{PAI}-1$ aktivasyonu ile ilişsilendirilmiştir ${ }^{15}$.

$\mathrm{Bu}$ çalışmada Güneydoğu Anadolu Bölgesi'nde TGK nedeniyle herediter trombofili parametreleri çalışılan hastaların sonuçlarının retrospektif olarak incelenmesi, bölgemizdeki ve ülkemizdeki sıklıklarının literatür verileri ışığında incelenmesi hedeflenmiştir.

\section{YÖNTEMLER}

Harran Üniversitesi Tıp Fakültesi Tıbbı Genetik Anabilim Dalı'na Ekim 2016- Aralık 2017 tarihleri arasında tekrarlayan düşük nedeniyle Şanlıurfa, Gaziantep, Adıyaman, Diyarbakır, Mardin ve Şırnak illerinden başvuran, 18-50 yaş arası, kromozom analizi sonucu herhangi bir anomali tespit edilmeyen 1395 birey retrospektif olarak çalışmaya dahil edilmiştir. Hastaların demografik bilgileri ve abort sayıları dosyalarından öğrenilmiş ve not edilmiştir. Çalışmaya dahil edilen 1395 hastadan 3ml'lik ethylene diamine tetra-acetic acid (EDTA) içeren tüplere alınan kan örneklerinden Magpurix Blood DNA Extraction Kit 200 ile
DNA izole edildi. Elde edilen DNA örneklerinin Nanodrop SMA1000 spektrofotometre cihazında miktar ve saflık tayinleri yapıldıktan sonra Qubit 3 fluorometer (İnvitrogen , Türkiye) cihazında da florometrik tayin yapıldı ve DNA örnekleri polimeraz zincir reaksiyonu (PCR) işlemi yapılana kadar uygun koşullarda bekletildi. PCR işlemi BIORAD T100TM Thermal Cycler (Türkiye) termal döngü cihazında yapıldıktan sonra Faktör V Leiden (R534Q), Faktör II (Protrombin), Serpine-1 (PAI-1 4G/5G) Insersiyon, MTHFR C677T ve MTHFR A1298C polimorfizmlerinin saptanması için Yeni Nesil Sekanslama (NGS;Next Generation Sequencing) yöntemini kullanarak üreticinin öngördüğü protokol uyarınca Miniseq (Illumina GmbH, Almanya) cihazı ile sekanslama yapıldı. Kullanılan forward primer dizileri; MTHFR C677T için 5'TGAAGGAGAAGGTGTCTGCGGGA3', MTHFR A1298C için 5'GGTCCCCACTTCCAGCATC3', Faktör V Leiden için 5' GGAACAACACCATGATCAGAGCA3', Protrombin için 5'TCTAGAAACAGTTGCCTGGC3', PAI-1 için ise 5'AAGCTTTTACCATGGTAACCCCTGGT3' şeklinde idi. Veriler Microsoft Excel programına girilerek SPSS 13.0 programı ile incelendi. Çalışmamız Harran Üniversitesi Etik Kurulu tarafından 2018 Ocak ayında onay almıştır.

\section{SONUÇLAR}

Çalışmaya katılan hastaların ortalama yaşı 29.74, medyan yaş ise 29 olarak bulundu. Hastaların abort sayısı ortalaması 3,34 olarak tespit edildi. Çalışmaya katılan hastaların başvuru yaptığı iller incelendiğinde; \%64 Şanlıurfa, \%14 Mardin, \%12 Adıyaman, \%6 Diyarbakır, \%2 Gaziantep ve \%2 Şırnak dağılımı gözlenmiștir (Tablo 1). MTHFR C677T polimorfizmi $732(\% 52,5)$ hastada yabanıl tipte, $538(\% 38,6)$ hastada heterozigot, 125(\%9) hastada ise homozigot olarak gözlendi. MTHFR A1298C polimorfizmi 1392 hastada değerlendirildi, hastaların 514'ünde $(\% 36,9)$ yabanıl tip gözlenirken, 644'ünde $(\% 46,3)$ heterozigot, 234'ünde $(\% 16,8)$ ise homozigot 
olarak gözlendi. Protrombin G20210A polimorfizmi $1339(\% 96)$ hastada yabanil tipte gözlenirken, 56(\%4) hastada heterozigot olarak gözlendi. $\mathrm{Bu}$ polimorfizme homozigot olarak sahip olan herhangi bir hasta yoktu. FVLeiden polimorfizmi ise 1301(\%93,3) hastada yabanıl tip, 87(\%6.2) hastada heterozigot, $7(\% 5)$ hastada da homozigot olarak değerlendirildi. $\quad 1371 \quad$ hastada değerlendirilebilen PAI-1 polimorfizminde yabanıl tip 437(\%31,3), heterozigot tip $651(\% 46,7)$ ve homozigot tip 283(\%20.3) hastada gözlendi (Tablo 2). MTHFR'de gözlenen iki polimorfizm için de yabanıl tip gösteren hasta sayısı 161(\%11,5), heterozigotluk gösteren hasta sayıs $338(\% 24,2)$, homozigotluk gösteren hasta sayısı $23(\% 1,65)$ olarak bulundu. İncelenen tüm bölgelerin hepsinde yabanıl tipe sahip hasta sayısı ise sadece $42(\% 3)$ olarak bulundu. İncelenen tüm parametreler içinde 598(\%42,9) hasta en az bir homozigot değişikliğe sahip olarak tespit edildi.

Tablo 1: Katılımcıların Demografik, Klinik ve Coğrafi Özellikleri

\begin{tabular}{|lc|}
\hline & Demografik ve Klinik Veriler \\
\hline Ortalama Yaş & 29.74 \\
Medyan Yaş & 29 \\
Ortalama Abort Sayısı & 3.34 \\
& Başvuru Yapılan IIller (\%) \\
Şanlıurfa & 64 \\
Mardin & 14 \\
Adıyaman & 12 \\
Diyarbakır & 6 \\
Gaziantep & 2 \\
Şırnak & 2 \\
\hline Toplam & $\mathbf{1 0 0}$ \\
\hline
\end{tabular}

\section{TARTIŞMA}

$\mathrm{Bu}$ çalışmada Güneydoğu Anadolu Bölgesi'nin çeşitli illerinden tekrarlayan gebelik kaybı nedeni ile polikliniğimize başvuran hastalarda MTHFR C677T, MTHFR A1298C, Protrombin G20210A, FV-Leiden ve PAI-1 polimorfizmleri incelenmiştir. MTHFR geni 1p36.23-p34.3 bölgesinde yer alır ve 11 ekzondan oluşur. MTHFR gen polimorfizmleri hiperhomosisteinemiye yol açarak, abort riskini artırmaktadır. C677T polimorfizmi, enzimi isıya hassas bir hale getirerek, MTHFR aktivitesini \%35-70 oranında azaltır. A1298C poliorfizminde ise enzim aktivitesi \%40 kadar azalmasına rağmen plazma homosistein düzeylerinde anlamlı bir değişim gözlenmemiştir ${ }^{12}$. MTHFR aktivitesinde azalmaya bağlı oluşan hiperhomosisteinemi, sadece aşırı düzey folat, B6, B12 vitamin eksikliğinde belirgin hale gelir. Bir meta-analiz çalışmasında, tekrarlayan gebelik kaybı olan hastalardaki MTHFR C677T homozigot sıklığı \%5-21 oranında gözlenirken kontrol grubunda \%4-20 oranında gözlenmiş olup, istatiksel olarak anlamlı bir fark tespit edilmemiştir. Yine aynı yayında hiperhomosisteinemi tekrarlayan gebelik kaybı olgularında \%17-27 oranında gözlenirken, kontrol grubunda \%5-16 oranında gözlenmiş ve 3-7 kat risk artışı ile ilişkilendirilmiștir ${ }^{16}$. Bu durum MTHFR polimorfizmlerinin klinik olarak gözlenebilmesi için bireyde folat ya da B6, B12 vitaminlerinden birinin eksikliğinin olması gerektiği şeklinde yorumlanabilir. Başka bir meta-analiz çalışmasında folat ya da B6 ve B12 vitamini eksikliği olmayan kişilerde MTHFR polimorfizmlerinin tekrarlayan gebelik kayıpları ile ilișkili olmadığı gösterilmiștir ${ }^{17,18}$. Türkiye genelinde tekrarlayan gebelik kaybı ve MTHFR polimorfizminin incelendiği bir çalışmada heterozigotluk \%36,9, homozigotluk $\% 3,5$ olarak gözlenirken, Şanlıurfa ilinde yapılan bir çalışmada heterozigotluk \%40,61, homozigotluk \%8,29 oranında gözlenmiştir ${ }^{19}$. Bizim çalışmamızda ise heterozigotluk \%38,6, homozigotluk \%9 oranında gözlenerek, bölgesel veriler ile uyumlu bulunmuştur.

Protrombin geni 11. kromozomun uzun kolunda yerleşik bir gendir. G20210A polimorfizmi yüksek plazma protrombin düzeyleri ile ilişskili olup, yaklaşık 3 kat artmış tromboz riski taşımaktadır18,20,21. FV- 
Leiden'den sonra kalıtsal trombofili nedenleri arasında en sık gözlenen değişikliktir. Yapılan bir çalışmada G20210A polimorfizminin tekrarlayan gebelik kaybı olan olgularda \%2-3 oranında görüldügü gözlenmiștir ${ }^{2}$. Ülkemizde yapılan bir çalışmada heterozigot G20210A polimorfizmi venöz tromboz gözlenen olgularda \%1,2 olarak saptanmıștır ${ }^{22}$. Kujovic ve ark. tarafından yapılan çalışmada tekrarlayan gebelik kaybı olan olgularda bu polimorfizm \%4-13 oranında gözlenirken, kontrol grubunda bu oranın \%1-3 düzeyinde olması dikkat çekicidir ${ }^{16}$. Şanlıurfa ilinde tekrarlayan gebelik kaybi olan olgularda bu oran \%4,05 olarak bulunmuş, çalışmamız ile birebir paralellik göstermiștir ${ }^{19}$.

Tablo 2: Herediter Trombofili ile İlkişkili Polimorfizmlerin Görülme Sıklığı

\begin{tabular}{|l|c|c|c|c|c|}
\hline $\begin{array}{l}\text { GÖRÜLME } \\
\text { SIKILIĞI (\%) }\end{array}$ & $\begin{array}{c}\text { MTHFR } \\
\text { C677T }\end{array}$ & $\begin{array}{c}\text { MTHFR } \\
\text { A1298C }\end{array}$ & $\begin{array}{c}\text { PROTROMBIN } \\
\text { G20210A }\end{array}$ & FV LEIDEN & PAI-1 \\
\hline YABANIL & 52,5 & 36,9 & 96 & 93,3 & 31,3 \\
\hline HETEROZIGOT & 38,6 & 46,3 & 4 & 6,2 & 46,7 \\
\hline HOMOZIGOT & 9 & 16,8 & 0 &, 5 & 20,3 \\
\hline
\end{tabular}

FV-Leiden polimorfizmi, 1943 yılında tanımlanan Faktör V proteinindeki 506. Pozisyonda yer alan glutaminin yerine arjininin geçmesi sonucu oluşur ${ }^{23}$. En sık herediter trombofili nedenidir. Tüm herediter trombofili vakalarının yaklaşık yarısından sorumludur ${ }^{13}$. Heterozigotlarda yaklaşı 10 kat, homozigotlarda ise yaklaşık 100 kat artmış tromboz riski mevcuttur. Faktör V-Leiden polimorfizmi nedeniyle var olan trombotik eğilimin, gebeliklerde uteroplasental yatakta tromboza neden olabileceği çeşitli çalışmalar ile kanıtlanmıștır ${ }^{14,18,20}$. Kujovich ve ark. tarafından yapılan çalışmada gebelik kaybı riskini 2-5 kat artırdığı gösterilmiştir ${ }^{16}$. Şanlıurfa ilinde tekrarlayan gebelik kayıpları olan bireylerde yapılan bir çalışmada FVLeiden heterozigotluk oranı $\% 5,5$, homozigotluk oranı ise $\%, 2$ olarak bulunmuştur $^{19}$. Sivas ilinde yapılan bir populasyon taraması çalışmasında homozigotluk \%,4 olarak bulunmuștur ${ }^{24}$. Çalışmamızda bu oranlar heterozigotluk için $\% 6,2$, homozigotluk için \%,5 olarak bulunmuştur.

Serpine-1 olarak da adlandırılan PAI-1 geni 7 . kromozomun uzun kolunda lokalizedir. 4G alleli 5G alleline göre transkripsiyonel açıdan daha aktifitr. PAI-1 etkinliğinin daha yüksek olduğu 4G/4G polimorfizminin gebelik kayıplarıyla ilişkisi olabileceğini gösteren çalışmalar mevcuttur25. Sivas ve Muş illerinde yapılan bir çalışmada tekrarlayan gebelik kaybı olan olgularda PAI-1 homozigot değişiklik oranı $\% 25$ ve \%30 olarak bulunmuştur, çalışmamızda bu oranın \%20,3 olarak bulunması dikkat çekicidir $26,27$.

İncelenen tüm polimorfizmler içinde en az bir homozigot değișikliğe sahip hasta oranının $\% 42,9$, tüm polimorfizmler için yabanıl tip gösteren hasta oranının yalnız \%3 olarak gözlenmesi, Kujovich ve ark. tarafından yapılan çalışmada da bahsedildiği gibi kombine trombofili kavramının önemine işaret etmektedir. İlgili çalışmada kombine trombofili kavramaının tekrarlayan gebelik kaybını 5-14 kat artırdığ

Tekrarlayan gebelik kayıplarında herediter trombofililerin yeri hala güncel bir tartışma konusudur, son dönemlerde yapılan yayınlarda polimorfizmlerin etkilerinin gebeliğin hangi safhasında (erken-geç) düşüklere neden olduğunu araştıran araştırmaların sayısı artmaktadır. Son zamanlarda değer kazanan diğer bir kavram da herediter trombofili nedenlerinin beraber gözlenmesi olarak adlandırılabilecek olan kombine trombofili kavramıdır. Çalışmamız, polimorfizm çalışmalarının geniş örneklemli popülasyonlarda çalışılmasının önemli olması ve hastaların kromozom analizi sonuçlarının değerlendirilip, herhangi bir anomaliye sahip olanlanların çalışmaya alınmaması nedeniyle değerli olup, en önemli dezavantajı çalışmanın retrospektif olarak yapılması ve gebelik kayıp haftalarının erken-geç olarak ayrılmasındaki 
eksikliğidir. Sonuç olarak, bölgemizdeki tekrarlayan gebelik kaybı olan 1395 hasta retrospektif olarak incelenmiş; bölgesel polimorfik varyantların dağılımı güncel bilgiler ışığında, bölgesel ve ülkesel veriler eşliğinde tartışılmıştır.

Teşekkür: Çalışmaya katılan tüm hastalara içtenlikle teşekkür ederiz.

Çıkar Çatışması Beyanı: Yazarlar çıkar çatışması olmadığını bildirmişlerdir.

Finansal Destek: Bu çalışma her hangi bir fon tarafından desteklenmemiştir.

Declaration of Conflicting Interests: The authors declare that they have no conflict of interest.

Financial Disclosure: No financial support was received.

\section{KAYNAKLAR}

1. Kolte AM, Bernardi LA, Christiansen OB, et al. Terminology for pregnancy loss prior to viability: a consensus statement from the ESHRE early pregnancy special interest group. Hum Reprod. 2015; 30: 495-8.

2. Stephenson M, Kutteh W. Evaluation and Management of Recurrent Early Pregnancy Loss. Clin Obstet Gynecol. 2007; 50: 132-45.

3. Jauniaux E, Farquharson RG, Christiansen OB, Exalto N. Evidence-based guidelines for the investigation and medical treatment of recurrent miscarriage. Hum Reprod. 2006; 21: 2216-22.

4. Greer IA. Thrombophilia: implications for pregnancy outcome. Thromb Res. 2003; 109: 73-81.

5. Regan L, Braude PR, Trembath PL. Influence of past reproductive performance on risk of spontaneous abortion. BMJ. 1989; 299: 541-5.

6. Pitas RE, Boyles JK, Lee SH, Foss D, Mahley RW. Astrocytes synthesize apolipoprotein E and metabolize apolipoprotein E-containing lipoproteins. Biochim Biophys Acta (BBA)/Lipids Lipid Metab. 1987; 917: 148-61.

7. Li TC, Makris M, Tomsu M, Tuckerman E, Laird S. Recurrent miscarriage: aetiology, management and prognosis. Hum Reprod Update. 2002; 8: 463-81.

8. American College of Obstetricians and Gynecologists. ACOG practice bulletin. Management of recurrent pregnancy loss. Int J Gynaecol Obstet. 2002; 78: 179-90.

9. Katz V, Kuller J. Recurrent Miscarriage. Am J Perinatol. 1994; 11: 386-97.
10. Buchholz T, Thaler CJ. Inherited Thrombophilia: Impact on Human Reproduction. Am J Reprod Immunol. 2003; 50: 20-32.

11. İzmirli M, Aldemir Ö, Gögebakan B, Alptekin D. The studies about diseases concerning with contemplated MTHFR 677 C>T polymorphism. Dicle Med Journal/Dicle Tıp Derg. 2014; 41: 244-56.

12. Wu X, Zhao L, Zhu H, He D, Tang W, Luo Y. Association Between the MTHFR C677T Polymorphism and Recurrent Pregnancy Loss: A Meta-Analysis. Genet Test Mol Biomarkers. 2012; 16: 806-11.

13. Sergi C, Al Jishi T, Walker $M$. Factor V Leiden mutation in women with early recurrent pregnancy loss: a meta-analysis and systematic review of the causal association. Arch Gynecol Obstet. 2015; 291: 671-9.

14. Gerhardt A, Scharf RE, Beckmann MW, et al. Prothrombin and Factor V Mutations in Women with a History of Thrombosis during Pregnancy and the Puerperium. N Engl J Med. 2000; 342: 374-80.

15. Salazar Garcia MD, Sung N, Mullenix TM, et al. Plasminogen Activator Inhibitor-1 4G/5G Polymorphism is Associated with Reproductive Failure: Metabolic, Hormonal, and Immune Profiles. Am J Reprod Immunol. 2016; 76: 70-81.

16. Kujovich JL. Thrombophilia and pregnancy complications. Am J Obstet Gynecol. 2004; 191: 412-24.

17. Rey E, Kahn SR, David M, Shrier I. Thrombophilic disorders and fetal loss: a meta-analysis. Lancet. 2003; 361: 901-8.

18. Foka ZJ, Lambropoulos AF, Saravelos H, et al. Factor V leiden and prothrombin G20210A mutations, but not methylenetetrahydrofolate reductase C677T, are associated with recurrent miscarriages. Hum Reprod. 2000; 15: 458-62.

19. Incebiyik A, Hilali NG, Camuzcuoglu $A$, et al. Prevalence of thromogenic gene mutations in women with recurrent miscarriage: A retrospective study of 1,507 patients. Obstet Gynecol Sci. 2014; 57: 513-7.

20. Friedline JA, Ahmad E, Garcia D, et al. Combined factor $\mathrm{V}$ Leiden and prothrombin genotyping in patients presenting with thromboembolic episodes. Arch Pathol Lab Med. 2001; 125: 105-11.

21. Bilici M, Öz İI, İlikhan SU, et al. The predictive value of factor V Leiden, prothrombin G20210A and MTHFR C677T Gene mutations on the location of venous thromboembolism. Dicle Med J / Dicle Tip Derg. 2015; 42: 467-71.

22. Ayyildiz 0, Kalkanli S, Batun S, et al. Prothrombin G20210A gene mutation with LightCycler polymerase chain reaction in venous thrombosis and healthy population in the southeast of Turkey. Heart Vessels. 2004; 19: 164-6. 
23. Cripe LD, Moore KD, Kane WH. Structure of the gene for human coagulation factor V. Biochemistry. 1992; 31: $3777-85$.

24. Özen F, Koçak N, Ejder Yıldırım $M$, et al. Sivas Populasyonunda Faktör V Genin Leiden (G1691a) ve Hr2 (A4070g) Polimorfizmleri. İnönü Üniversitesi Tıp Fakültesi Derg. 2009; 16: 179-83.

25. Dossenbach-Glaninger A, van Trotsenburg $M$, Dossenbach $\mathrm{M}$, et al. Plasminogen activator inhibitor 1 4G/5G polymorphism and coagulation factor XIII Val34Leu polymorphism: impaired fibrinolysis and early pregnancy loss. Clin Chem. 2003; 49: 1081-6.
26. Ejder Yıldırım M, Dağ Ş, Küçük Kurtulgan $H$, et al. Plazminojen aktivatör inhibitör-1 (PAI-1) 4G/4G polimorfizminin gebelik kayıplarıyla ilișkisi The association of plasminogen activator inhibitor-1 (PAI1) $4 G / 4 G$ polymorphism with miscarriages. Cumhur Tip Derg/Cumhur Med J. 2014; 36: 350-5.

27. Bayram B, Kılıççı Ç, Bozarı S, Onlu H, Sahin F. Muş İlinde Tekrarlayan Gebelik Kayıpları İle Mthfr C677t ve A1298c ve Pai-1 4g/5g Polimorfizmleri Arasindaki İlişki ve Alel rekansları. Kocatepe Tıp Derg. 2015; 12: 61-7. 